\title{
ATLAS DOS SETORES POSTAIS: UMA NOVA GEOGRAFIA A SERVIÇO DA EMPRESA
}

Francisco Aranha Professor do Departamento de Informática e Métodos Quantitativos da EAESP/FGV e Consultor de Empresas. E-mail: faranha@eaesp.fgvsp.br

RESUMO: O CEP - Código de Endereçamento Postal - pode ser utilizado como método de descrição de localizações. O Atlas de Setores Postais extrai as propriedades bidimensionais do CEP, apresentando o contorno das regiões postais brasileiras, das sub-regiões do Estado de São Paulo e dos setores do interior do Estado. As informações georeferenciadas do Atlas podem participar dos processos de tomada e implementação de decisões. Este artigo descreve como o Atlas dos Setores Postais está sendo desenvolvido e dá um exemplo de aplicação prática.

ABSTRACT: CEP - Brazilian Postal Code - can be used to describe locations. The Postal Code Atlas extracts bidimensional proporties from CEP, presenting the boundaries of brazilian postal regions; state of São Paulo Subregions, and state of São Paulo countryside sectors. Georeferenced information take part in decision making and implementation. This article describes how the Postal Code Atlas is being developed and offers an example of practical application.

PALAVRAS-CHAVE: estudos de localização, CEP, atlas de setores postais, informação georeferenciada, sistemas geográficos de informação, GIS

KEYWORDS: location studies, postal code, postal code atlas, georeferenced information, geographic information systems, GIS. 


\section{UMA NOVA GEOGRAFIA}

Para um número bastante significativo de profissionais a imagem de "Geografia" como área específica do conhecimento ficou congelada nos tempos de escola. Faz lembrar longas listas de países com suas capitais e parece servir, com pequenas variações, para saber onde acabam as savanas e começa a tundra. É pena: trata-se de uma imagem descolada da realidade. Apesar da leve aversão que pode ser provocada por este tipo de lembrança, a verdade é que, sem o percebermos, tornamo-nos, todos, especialistas em Geografia.

Fugindo do trânsito de São Paulo, escolhemos caminhos diferentes para chegar ao mesmo destino, em função da hora do dia; na empresa, decidimos pela abertura ou fechamento de filiais como adaptação a mudanças no mercado consumidor; no governo, planejamos o combate a doenças em áreas recentemente afetadas por inundações; no Mercosul discutimos a conveniência do novo Regime Automotivo para os estados do Nordeste e Centro-Oeste do Brasil.

Geografia é isso: manipulação de informações que podem ser referenciadas a localizações sobre a Terra; inter-relação entre pessoas e seu meio ambiente; observação de variações na estrutura de comportamento da sociedade. No entanto, devido à presença inevitável mas difusa destes temas, acabamos por arquivá-los em pastas mentais rotuladas não de "Geografia", mas de "Administração", "Marketing", "Política" ou "História".

Recuperar a disciplina como digna de entrosamento com as demais é urgente, pois abre muitas possibilidades de conhecimento e disponibiliza uma conjunto específico de poderosas ferramentas de análise.

Incorporando recursos da área de Geografia e Cartografia à Administração de Empresas, estamos desenvolvendo um projeto de pesquisa patrocinado pelo NPP - Núcleo de Pesquisa e Publicações da EAESP-FGV, com o objetivo de produzir um "Atlas dos Setores Postais do Interior do Estado de São Paulo".' Este artigo condensa e apresenta os principais conceitos e alguns dos resultados de pesquisa.

O Atlas propõe a utilização do Código de Endereçamento Postal como uma Geografia nova em dois sentidos: do ponto de vista subjetivo, pretende colocar-se dentre os esforços de ruptura com a imagem ultrapassada da disciplina, resgatando uma "especialização" de que já dispomos; e do ponto de vista tecnológico, intenciona beneficiar-se das radicais mudanças introduzidas pelo emprego de Sistemas Geográficos de Informação (GIS), 2 "o maior avanço na geografia desde a introdução do uso de mapas". 3

\section{Estratégias de localização}

Há inúmeros métodos alternativos para identificarmos uma localidade, ou, em termos um pouco mais precisos, "descrever uma localização". Cada um destes métodos é mais adequado a uma particular finalidade, e cada um tem propriedades e desvantagens inerentes. ${ }^{4}$ Vejamos alguns.

A geometria global permite localizarmo-nos a partir de pontos fixos de referência sobre a Terra: por exemplo, a EAESP-FGV está situada a $23,56^{\circ}$ ao Sul do Equador e $46,65^{\circ}$ a Oeste de Greenwich. Este tipo de opção funciona bem para grandes áreas, permite o cálculo de distâncias entre dois objetos e pode ser utilizada em qualquer nível de detalhe pelo aumento de casas decimais. Mas não é "natural": fornecida a um motorista de táxi, num ponto qualquer da cidade de São Paulo, dificilmente esta informação levaria o passageiro até a Escola.

A geometria local define um lugar em relação a outros que lhe são próximos e oferece um código mais amigável. "A GV fica logo depois do túnel da Nove de Julho, no sentido bairro-centro" é o tipo de afirmação fácil de entender. Embora consista num método indispensável em Tóquio, onde a maioria dos cartões de visita contém um pequeno mapa indicando a posição do endereço em relação a marcos locais, não funciona muito bem quando estamos trabalhando com grandes distâncias, nem em regiões, como a rural, em que pontos de referência são escassos. Além disso, apresenta o inconveniente de não permitir relacionar entre si dois objetos referidos a marcos diferentes.

A topologia local faz uso dos acidentes geográficos e também é bastante usada, embora não permita estimar distâncias. Na minha experiência pessoal, "o camping fica logo aí, depois da primeira lombada", já significou uma caminhada de seis quilômetros, o que não corresponde exatamente ao meu conceito de "logo aî". Obviamente, não se podem fazer mapas nestas bases.

Seqüências de estruturas hierarquizadas também são simples de entender e correspondem a estruturas do mundo real: "segunda rua à esquerda, terceira casa à direita". Trata-se de uma opção simples e natural, que permite esti-
1. 0 estudo está em fase adiantada devendo ser publicado ainda neste primeiro semestre de 1997. Na continuidade do projeto, deveremos estender a abrangência do Atlas para a Região Metropolitana de São Paulo.

2. A sigla "GIS", que preferimos a "SGI" por ser mais eufônica, vem da denominação original em inglês: "Geographic Information Systems". Em decorrência da ambigüidade existente na nomenclatura original, que não permite definir a que substantivo ("information" ou "system") se prende 0 adjetivo "geographic", há uma controvérsia sobre qual seria a melhor tradução: "Sistema Geográfico de Informações", defendida por quem acha que o sistema é geográfico; e "Sistema de Informaçōes Geográficas", defendida por quem acha que as informações é que o são. A pendenga não deixa de ser engraçada, tal 0 ardor com que encontramos partidários das duas teses; em minha opinião, a especificidade do GIS é a forma como ele trata geograficamente a informação geográfica, de tal maneira que, diante da pouca praticidade da expressão "Sistema Geográfico de Informações Geográficas", uso indistintamente qualquer uma das duas formas em circulação.

3.DEPARTMENT OF THE ENVIRONMENT. Handling geographic information: the report of the government's Committee of

Enquire, London: Department of Environment, 1987.

4. A discussão a seguir foi resumida e adaptada de RAPER, Jonathan; RHIND, David; \& SHEPERD, John, Postcodes, London: Longman, 1992. 
mar algumas distâncias com maior precisão (no exemplo, a distância entre as casas) e outras com precisão menor (no exemplo, a distância entre as ruas).

Uma descrição nominal, a mais amplamente utilizada no dia-a-dia, nenhuma relação entre objetos pode ser derivada. "Moro no município de Xanxerê" não diz absolutamente nada, a menos que você já saiba onde fica Xanxerê e possa referenciá-lo por algum dos outros métodos. ${ }^{5}$

\section{CEPs: muito além de uma entrega mais rápida}

Inicialmente projetado para acelerar e reduzir o custo da entrega de correspondência, permitindo a separação automatizada dos objetos postais, os códigos de endereçamento acabaram desempenhando a função muito mais ampla de servir como uma linguagem hierarquizada e bastante consistente de descrição do espaço geográfico. Neste papel, seu uso disseminou-se pelas organizações não postais, e em particular pelas áreas de planejamento e marketing das empresas privadas, combinando características da estratégia de descrição nominal com elementos atenuados da estratégia de sequiências de estruturas hierarquizadas apresentada acima. Vejamos:

a) É um sistema nominal, na medida em que o código é atribuído arbitrariamente a uma localização. Os Correios delimitaram as áreas e as batizaram conforme sua conveniência. Saber que um acidente ocorreu no CEP 04042-034 não ajuda um piloto de helicóptero a levar a equipe de resgate até lá. É claro que as pessoas habituadas a raciocinar em termos de CEPs saberiam se localizar aproximadamente com base apenas no código postal, mas isso acontece porque, com a repetição reiterada de consultas a vários conjuntos de mapas convencionais, tornam-se capazes de referir mentalmente o CEP aos mapas.

b) É também um código hierárquico. Da maneira como foi construída, a estrutura do código postal brasileiro divide o território do país em regiões progressivamente menores, que se "aninham" dentro das maiores. Esta ordenação geográfica também fica refletida no sequienciamento de dígitos do radical do código.

Assim, a correspondência entre um núme-

5. A propósito: Xanxerê fica no extremo Oeste do Estado de Santa Catarina, a 400 km de Florianópolis, vizinho a Xaxim e Xavantina. terna e hierarquia cada vez mais específica, como veremos a seguir; e obedece, na medida do possível, algumas regras gerais como, por exemplo, o princípio de que a alocação seqüencial do radical dos códigos deve observar um padrão circular em sentido horário, ou o de que as áreas definidas devem conformarse a limites naturais como ferrovias, grandes logradouros, rios ou serras.

Note, no entanto, que a estrutura do CEP não corresponde necessariamente a estruturas do mundo real mas é definida arbitrariamente sobre elas (e, neste sentido, diverge da estratégia de utilização de seqüências de estruturas hierárquicas descrita no item anterior).

Em outras palavras, uma certa sequiência de dígitos pode se referir a um único edifício, enquanto a seguinte pode representar uma face de quadra, uma rua, ou todo um município; há casos, inclusive, em que o CEP nem mesmo reflete a existência de um ponto específico de entrega de correspondência, sendo atribuído a um esforço de marketing (por exemplo, a uma promoção que peça o envio de cartas, do tipo em que o consumidor junta uma certa quantidade de rótulos de um produto e os remete para a empresa, para participar de um sorteio).

\section{Estrutura espacial do CEP}

Todos os CEPs existentes são compostos por oito dígitos: os cinco primeiros formam um radical e são separados dos demais por um hífen; estes últimos, em número de três, formam o sufixo. Todos os conjuntos de oito dígitos podem ser organizados sequiencialmente em ordem numérica, como pontos ao longo de uma reta numerada.

Há bastante tempo, os usuários aprenderam a trabalhar com o CEP fazendo uso de suas propriedades de variável unidimensional discreta, armazenando-o em bancos de dados, e utilizando listas ou faixas de CEP para descrever determinadas localizações. Assim, por exemplo, os CEPs que vão de 01000-000 a 01099-999 correspondem aos bairros da Sé e República, do município de São Paulo.

Este tipo de abordagem, embora possibilite já uma certa especialização do código, não permite que se explore a dimensão propriamente geográfica das localizações, conforme ilustração 1. Em outras palavras, não permite saber, por exemplo, que a faixa 11600-000 a 11699-999 (Setor 116) fica mais próxima da faixa 11200-000 a 11299-999 (Se- 
tor 112$)$ do que da faixa $\mathbf{1 1 7 0 0 - 0 0 0 ~ a ~} \mathbf{1 1 7 9 9 -}$ 999 (Setor 117); também não permite saber quais faixas são adjacentes entre si.

Ilustração 1:

Sub-Regiāo 11 - Litoral do Estado de Sāo Paulo

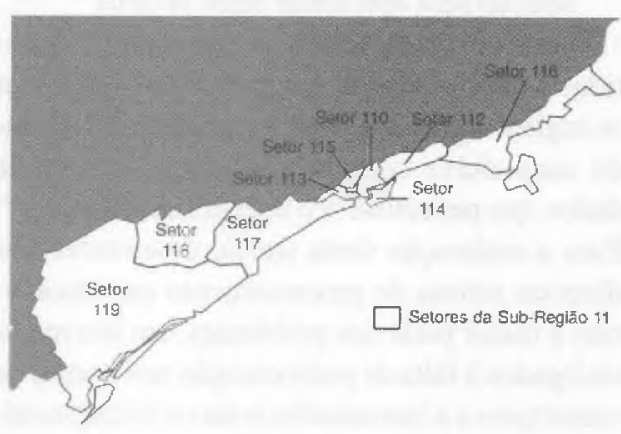

O objetivo do preparo deste Atlas do CEP foi, justamente, permitir a extração das propriedades bidimensionais do código postal, ajustando-o à superfície do território brasileiro de uma maneira georeferenciada e consistente. Vejamos o que acontece quando se estabelece este tipo de correspondência.

Primeiro dígito. $\mathrm{O}$ primeiro dígito do CEP define dez Regiōes Postais no Brasil, conforme a ilustração 2 a seguir.

llustraçăo 2: Regiōes Postais do Brasil

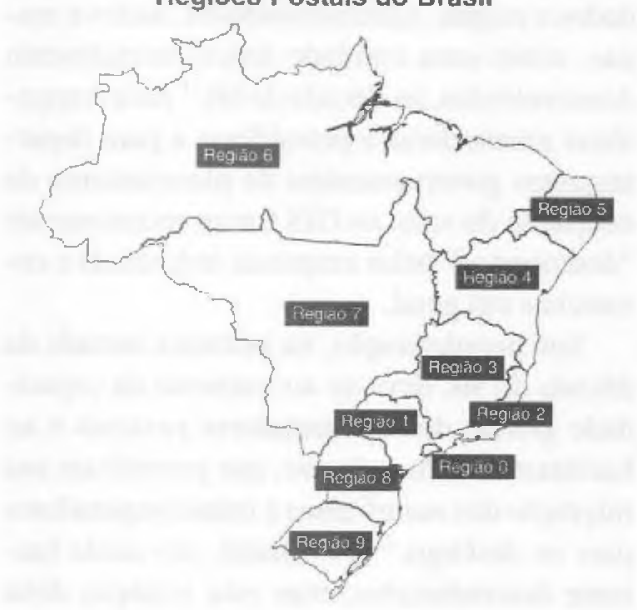

Todos os CEPs que iniciam com o dígito " 0 ", por exemplo, pertencem à Regiấo Postal 0 , que corresponde à Região Metropolitana de São Paulo. Os CEPs que iniciam pelo dígito " 1 " correspondem à Região Postal 1, isto é, ao interior do Estado de São Paulo. Os que começam por "2" pertencem à Região Postal 2, que abrange os Estados de Rio de Janeiro e Espírito Santo. E assim por diante.

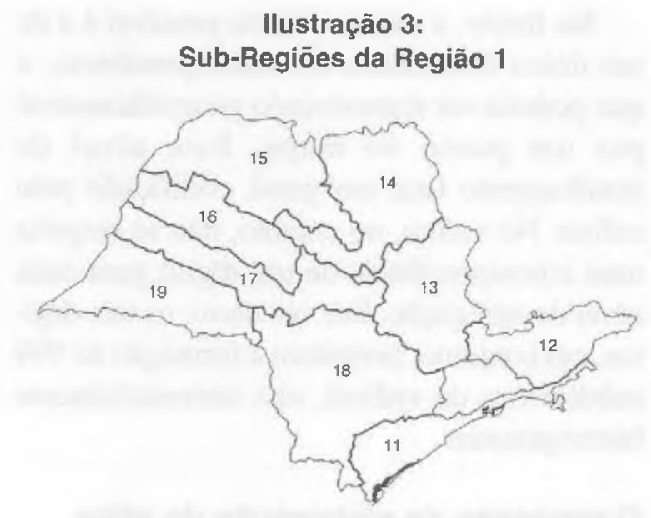

Segundo dígito. $\mathrm{O}$ segundo dígito do CEP divide as Regiões em Sub-Regiōes Postais. A ilustraçăo 3 mostra as nove Sub-Regiões do Interior do Estado de São Paulo, isto é, as SubRegiões 11 a 19 da Região Postal 1.

Note, por exemplo, que a Sub-Região 11 faz fronteira com as Sub-Regiōes 12 e 18, mas não com as demais. Este tipo de relação não pode ser derivado a partir de tabelas.

Terceiro dígito. A ilustração 1 já exibiu os Setores Postais da Sub-Região 11. O Setor 118, por exemplo, corresponde à faixa que vai de 11800-000 a 11899-999, isto é, abrange todos os CEPs que iniciam pelos dígitos " 118 ". $\mathrm{Na}$ prática, esta faixa de CEPs equivale ao território dos municípios de Juquiá e Miracatu.

Em resumo, o primeiro dígito do $\mathrm{CEP}$, tomado isoladamente, define Regiōes Postais; os dois primeiros, em conjunto, definem Sub-Regiōes; os três primeiros delimitam setores.

Assim, o nível de detalhamento da descrição geográfica que se pode obter a partir do CEP aumenta pela sucessiva subdivisão das regiões maiores em regiōes menores, mutuamente excludentes e conjuntamente exaustivas, aninhadas nas maiores. Em termos de código, esta divisão é representada pela consideração de mais dígitos do radical do CEP, segundo a estrutura ${ }^{6}$ apresentada a seguir:

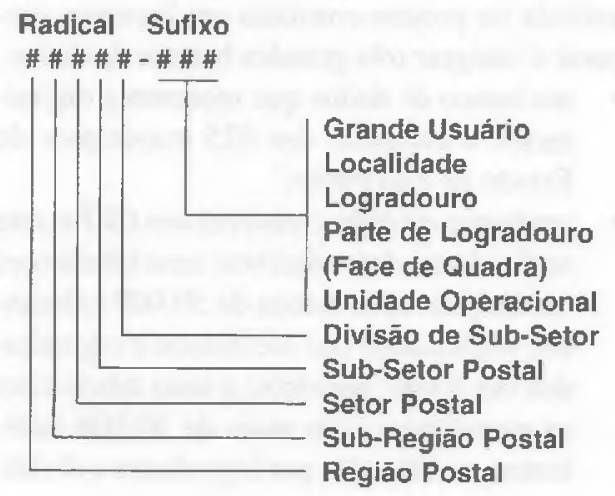

6. EMPRESA de Correios e Telégrafos. Guia de Codificação Postal, Diretoria Regional de São Paula, 1995. Documento Interno. 
7. Este tipo de arquivo, na verdade um mapa digital do Estado de São Paulo, pode ser comprado de um dos vários fornecedores comerciais de bases para Sistemas Geográficos de Informação; base especificamente utilizada neste projeto foi emprestada pela Paredro Administraçáo Ltda.

8. $O$ banco de dados de CEPs é fornecido gratuitamente pelos Correios; o usuário interessado deverá levar uma caixa de disquetes de 3,5" à rua Morgenthaler, 592 Bloco II, $14^{\circ}$ andar, São Paulo (Gerência Comercial).

9. Este banco de dados é vendido pela Fundação Seade, sob o nome de "Perfil Municipal"; utilizamos a edição de 1995 contendo dados até 1993.

10. A chave utilizada foi o código do IBGE para os municípios. Este código é formado por 6 digitos; os dois primeiros representam a unidade da federação e os 4 últimos correspondem ao número do município dentro da unidade da federação.

11. PAREDES, Evaristo. Sistemas de Informação Geográfica - S/G. São Paulo: Érica, 1994

12. ARANHA, Francisco. Sistemas de informação Geográfica: uma arma estratégica para o Database Marketing. In: RAE - Revista de Administração de Empresas. Săo Paulo: EAESP-FGV, v. 36 n.2, p12-6, Abr./Maio/Jun. 1996
No limite, a menor divisão possível é a de um único destinatário de correspondência, o que poderia ser representado geograficamente por um ponto no mapa. Este nível de detalhamento fica, em geral, codificado pelo sufixo. No sufixo, no entanto, não se respeita uma correspondência de um dígito para cada nível de agregação. Em vez disso, os três dígitos, em conjunto, permitem a formação de 999 subdivisões do radical, não necessariamente hierarquizadas.

\section{O processo de elaboração do atlas postal}

A elaboração do Atlas dos Setores Postais envolveu duas tarefas básicas:

- de um lado, tratamos os CEPs de forma a explicitar os contornos das regiões que definem; no projeto de pesquisa em que estamos trabalhando, isto foi feito em nível de Setores e apenas para o Interior do Estado de São Paulo;

- de outro lado, reorganizamos os dados que decidimos utilizar, de forma agregá-los de maneira compatível com as regiões delimitadas no passo anterior; embora esta etapa não esteja totalmente concluída, o Atlas deverá trazer dados de urbanização, demografia, educação, emprego, consumo de energia, valor adicionado dos municípios, saneamento e sistema bancário.

O objetivo do projeto desenvolvido para o Núcleo de Pesquisa e Publicação (NPP) não é tanto a apresentação do produto final, necessariamente restrito em virtude dos recursos disponíveis para sua realização, como a indicação do processo pelo qual as empresas podem desenvolver suas próprias bases.

\section{Preparação dos bancos de dados}

De maneira geral, a principal tarefa desenvolvida no projeto consistiu em levantar, preparar e integrar três grandes bancos de dados:

- um banco de dados que representa digitalmente o contorno dos 625 municípios do Estado de São Paulo;

- um banco de dados relativos aos CEPs; este se divide em dois arquivos: uma tabela com municípios com menos de 50.000 habitantes, codificados por localidade e organizados em 9.640 registros; e uma tabela com os municípios com mais de 50.000 habitantes, codificados por logradouro e dividi- dos por estados. O Estado de São Paulo está organizados em 130.153 registros; ${ }^{8}$

- um banco de dados a respeito dos municípios paulistas, contendo dados organizados em 12 temas e 72 variáveis, das quais fizemos uma seleção para apresentar neste projeto. ${ }^{9}$

Os arquivos descritos acima foram submetidos a um tratamento que procurou padronizar os registros para em seguida codificá-los, criando uma chave comum a todos os bancos de dados, que permitisse seu inter-relacionamento. ${ }^{10}$ Para a realização desta tarefa, desenvolvemos diversas rotinas de processamento que resolveram a maior parte dos problemas, em sua maioria ligados à falta de padronização nos nomes de municípios e à inconsistência na codificação original. No entanto, a fase que mais consumiu tempo e esforço no projeto, até o momento, foi a de conferência dos resultados e solução manual dos problemas e exceções encontrados durante a criação das chaves.

\section{Sistemas Geográficos de Informação}

Uma vez devidamente indexados segundo sua chave comum, os arquivos foram interconectados por meio de um Sistema Geográfico de Informação.

Os Sistemas Geográficos de Informações são programas que permitem ligar bancos de dados a mapas, administrando-os, dados e mapas, como uma entidade única. Inicialmente desenvolvidos, na década de $60,{ }^{11}$ para companhias mineradoras e petrolíferas e para departamentos governamentais de planejamento da ocupação do solo, os GIS foram recentemente “descobertos" pelas empresas industriais e comerciais em geral.

Sua popularização, na primeira metade da década de 90 , deve-se ao aumento da capacidade gráfica dos computadores pessoais e ao barateamento do software, que permitiram sua migração dos mainframes e minicomputadores para os desktops. ${ }^{12}$ No Brasil, são ainda bastante desconhecidos, mas esta situação deve mudar rapidamente.

O emprego de um GIS neste projeto foi indispensável tanto para a criação dos contornos dos Setores Postais, como para a reorganização dos dados.

Embora a utilização dos resultados obtidos com o "Atlas dos Setores Postais" seja possível sem este tipo de ferramenta, na maior parte das circunstâncias as empresas se beneficiarão em utilizá-lo para agregação e para cruzamen- 
to de suas próprias informações com as informạções apresentadas no Atlas.

\section{Elaboração dos contornos dos setores postais}

A estratégia adotada para montagem dos Setores Postais foi dividida em duas grandes linhas:

- uma para os setores que poderiam ser obtidos por agregação de municípios, isto é, aqueles setores cujos contornos coincidiam com o limite externo da união das áreas de alguns municípios;

- e outra para os setores formados por partes de municípios, uma vez que, neste caso, precisaríamos fazer um levantamento adicional de mapas, que permitisse o desmembramento das partes.

\begin{tabular}{|l|c|c|}
\hline \multirow{2}{*}{ MUNICIPIO } & \multicolumn{2}{|c|}{ FAIXA DE CEP } \\
\cline { 2 - 3 } & CEP INICIAL & CEP FINAL \\
\hline Araçatuba & $16000-000$ & $16129-999$ \\
Campinas & $17000-000$ & $17119-999$ \\
Pres. Prudente & $19000-000$ & $19159-999$ \\
Ribeirão Preto & $14000-000$ & $14114-999$ \\
Santos & $11000-000$ & $11249-999$ \\
Sorocaba & $18000-000$ & $18109-999$ \\
S. J. do R. Preto & $15000-000$ & $15099-999$ \\
Taubaté & $12000-000$ & $12119-999$ \\
\hline
\end{tabular}

A partir das faixas de CEPs constantes nas tabelas fornecidas pelos Correios, identificamos, no interior do Estado de São Paulo (Regiāo Postal 1), nove municípios que continham ou pertenciam a mais de um Setor Postal, e, portanto, caíam na segunda categoria, exigindo maior trabalho.

Vejamos o que significa abranger mais de um setor postal, através do exame do caso de Araçatuba: como os setores são definidos pelos três primeiros dígitos do CEP, a área deste município ocupa os setores 160 e 161 ; o primeiro setor é ocupado integralmente pelo município e o segundo, parcialmente. A faixa de CEPs que vai de 16129-001 a 16199-999 deveria, em princípio, corresponder a outro município ou parte de outro município.

Obtivemos as plantas destes nove municípios identificados como problemáticos. Para nossa surpresa, ao examiná-las detidamente, elas não indicavam, na prática, o uso de toda a faixa de CEPs constantes das listagens. Segun- do as informações que obtivemos em nossas pesquisas subsequientes, as faixas de CEP não utilizadas estavam vagas, reservadas para a codificação futura dos municípios em questão, mas não ainda em uso.

No caso de Araçatuba, por exemplo, verificamos que a faixa de 16200-000 a 16229999 estava, de fato, vaga. O restante do Setor 162 estava atribuído ao município de Santo Antônio de Aracanguá e seus distritos. Enquanto a faixa inicial do Setor não for atribuída a localizações de Araçatuba, os limites de Santo Antônio e do Setor 162 coincidirão.

O mesmo tipo de situação se repetiu com os demais municípios da lista. De forma que, até que sua codificação seja reformulada, provavelmente por ocasião da codificação por logradouros, seu perímetro recai integralmente na faixa básica, isto é, no setor inicial da faixa.

Diante disto, um único procedimento foi utilizado para todos os municípios da Região 1 , isto é, todos os grupos de cidades abrangidas por um Setor Postal foram individualmente selecionados e seus contornos fundidos, com a utilização do recurso de consolidação de áreas disponivel no GIS.

Este processo resultou no desenho dos 86 Setores Postais da Região 1, isto é, do Interior do Estado de São Paulo, conforme ilustração 4.

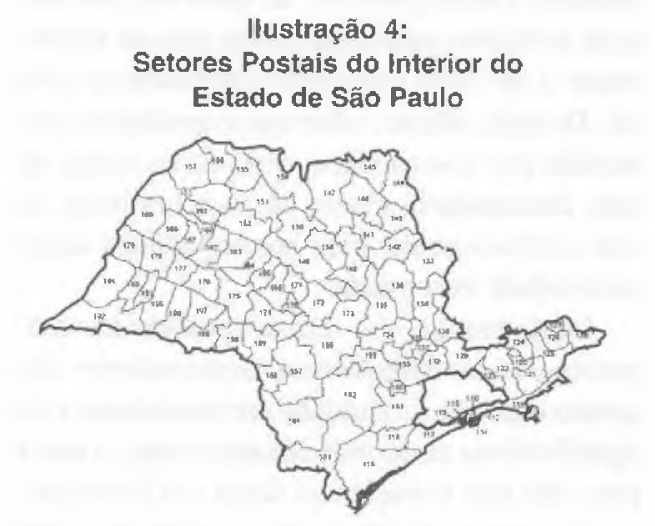

\section{Transformando informação geográficas em decisões}

Qualquer profissional habituado a trabalhar com informação sabe que hoje ela é crucial para o sucesso das empresas. "As organizaçôes bem-sucedidas na passagem para a era da informação serão as mais capazes de enxergar a informação como um ativo - um recurso - e desenvolver uma estratégia para lidar efetivamente com a alocaçāo deste tipo de recurso". 13
13. MEIRELLES, Fernando de Souza, informatica: Novas aplicacōes com microcomputadores, 2 ed., São Paulo: Makron Books, 1994. Citado de memória. 
Da mesma forma que os demais tipos de ativo, a informação tem custo e valor. Seu custo pode ser identificado com os dispêndios dos diversos tipos de recursos necessários à sua obtenção. Seu valor, contudo, não pode ser facilmente estabelecido: o principal problema decorre de que o valor da informação não é intrínseco, mas varia de usuário para usuário, conforme sua capacidade, preparo técnico e criatividade.

Uma abordagem possível para a resolução do problema consiste em considerar o valor da informação como a diferença líquida entre o resultado da atividade empreendida com o seu uso e o resultado que seria obtido sem ela. Assim, o valor da informação está intimamente ligada aos processos de tomada e implementação de decisões: administrar informação é transformá-la em ação.

A possibilidade de um usuário colocar um determinado conjunto de informações em movimento, por sua vez, está diretamente relacionada à capacidade de relacioná-la com outras informações. Em suma, depende de sua capacidade de fazer ligações.

Por exemplo: o benefício que uma empresa pode obter com a realização de uma pesquisa sobre o perfil dos seus clientes, consumidores de um determinado tipo de produto, vai depender de como consegue cruzar dados econômicos e demográficos, de quão eficazmente pode localizar aquele particular tipo de consumidor e de como consegue comunicar-se com ele. De nada adianta saber que o produto é consumido por jovens numa certa faixa etária, de uma determinada classe sócio-econômica, se este conhecimento ficar inerte, apenas como curiosidade desconexa.

Infelizmente, isso tem acontecido nas empresas com uma freqüência surpreendente: não apenas elas têm dificuldade em estabelecer elos significativos entre indicadores, como, o que é pior, não têm consciência desta sua limitação.

Em nossa atividade de consultoria temos constatado que a facilidade de manutenção e manipulação de planilhas eletrônicas e os variados recursos das novas impressoras estão patrocinando uma inundação de documentos, coloridos e bem editorados, tão numerosos e variados quanto inúteis. A papelada, devidamente encadernada e com uma capa de relatório mensal, acaba ocultando a inexistência de informações que tenham significado prático para a atuação da empresa.

Isto deve ser evitado a todo custo: as organizações nem devem deixar informação útil ador- mecida em seus arquivos, nem colecionar dados sem utilidade, ainda que muito interessantes.

Voltemos à questão da capacidade de fazer relações. A possibilidade de cruzamento de dados é freqüentemente uma questão difícil, já que geralmente os dados primários são coletados por várias organizações e institutos, que os processam de maneira a atender suas próprias finalidades e conveniências, não necessariamente coincidentes com as do usuário empresarial.

Tipicamente, os dados para grandes regiões geográficas, como os censitários e demográficos, são recolhidos e atualizados apenas em intervalos de vários anos, divulgados com elevado grau de agregação, e frequientemente com grande atraso... Outros tipos de dados, como os de acompanhamento de mercado ou relativos à operação da empresa, são coletados com detalhe bem maior e em periodicidade muito mais freqüente: há serviços de acompanhamento de penetração de marcas no comércio varejista, por exemplo, com regularidade bimestral; a circulação de uma revista, pode ser estudada semanalmente e agregada segundo as áreas de distribuição da editora; a quantidade de ligações que entram numa central de telemarketing costuma ser acompanhada diariamente, ou mesmo de hora em hora. Em outras palavras, quanto menor a abrangência dos dados, e mais próximos das operações regulares da empresa eles estiverem, maior sua disponibilidade $\mathrm{e}$ freqüência de mensuração.

Em vista disso, surge a pergunta de como proceder diante da necessidade de compatibilizar dados mantidos em formatos diferentes, com diferentes tipos de agregação, medidos em diferentes peridiocidades, relativos a regiões geográficas que não se encaixam perfeitamente entre si. Eles podem ser tão disparatados em sua natureza quanto, digamos, os elementos a seguir, usados para prever o consumo de refrigerantes (ilustração 5):

- registros pluviométricos e de temperatura;

- informações do cadastro imobiliário da prefeitura;

- população e renda dos moradores;

- consumo per capita de salgadinhos industrializados; $\mathrm{e}$

- potencial de consumo de Coca-Cola.

Uma possibilidade bastante prática é utilizar a localização dos fenômenos como chave relacional. Tudo que acontece, acontece em algum lugar; sabendo onde os fenômenos acon- 
tecem, portanto, podemos alavancar o poder da informação. Além disso, duas coisas que estão próximas tendem a ser mais parecidas do que duas que estão distantes, e esta propriedade permite estabelecer padrōes e fazer inferência.

Ilustraçāo 5:

Poder da integração geográflca de dados

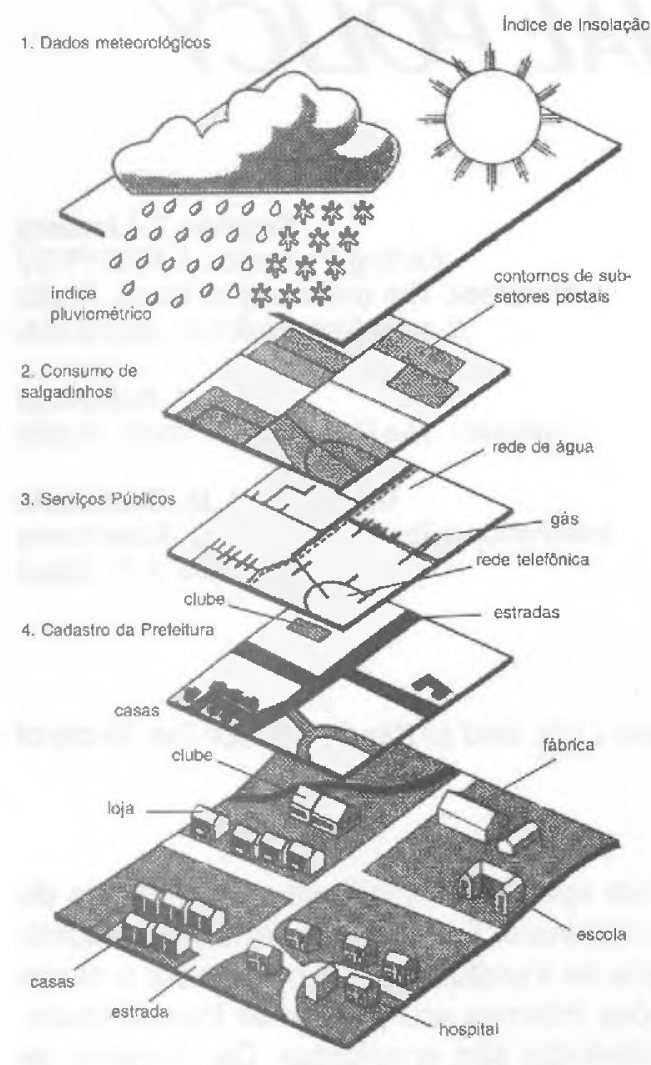

Em conseqüência, justamente, de sua capacidade de organização e integração de dados e de evidenciamento de padrões, é que a geografia oferece poderosos instrumentos de análise de problemas empresarias. ${ }^{14}$

É neste contexto que propomos a utilização do CEP como forma de descrição do componente geográfico dos fenômenos. Trata-se de um dado amplamente disponível a respeito das entidades com que a empresa trabalba: seu cadastro de clientes, fornecedores e competidores, por exemplo, quase com certeza já o inclui sistematicamente. Outros tipos de cadastro que podem interessar particularmente a um ou outro tipo de empresa, como, por exemplo, um banco de dados sobre localização de telefones públicos ou sobre a ocorrência de acidentes de trânsito, podem facilmente ser adaptados para passar a conter o código postal do objeto de interesse.

\section{CONCLUSÃO: APLICANDO INFORMAÇÕES GEOGRÁFICAS}

O objetivo final da elaboração do Atlas dos Setores Postais é permitir, a partir do CEP, que as empresas localizem seus dados de interesse, cruzando-os com outras informações, demográficas e sócio-econômicas. Neste artigo, apresentamos os contornos dos Setores Postais em prévia do projeto de pesquisa. Um conjunto de dados compatíveis com as regiões delimitadas será apresentado no relatório do NPP. Mas para concluirmos o artigo, gostaríamos de apresentar um exemplo de aplicação prática, com dados apresentados graficamente. ${ }^{15}$

Exemplo de aplicação. Imagine que uma empresa de produtos eletro-eletrônicos deseja escolher, para participar de uma promoção no ponto de venda, os seus revendedores do interior do Estado de São Paulo localizados em regiões de elevado consumo de energia elétrica por unidade domiciliar. ${ }^{16}$ Consultando o mapa da ilustração 6, descobre que deve escolher os revendedores cujo CEP pertençam aos Setores $120,122,123,124,129,130,132$ a 136,141 , $146,148,151,160,170,191$ e 180 .

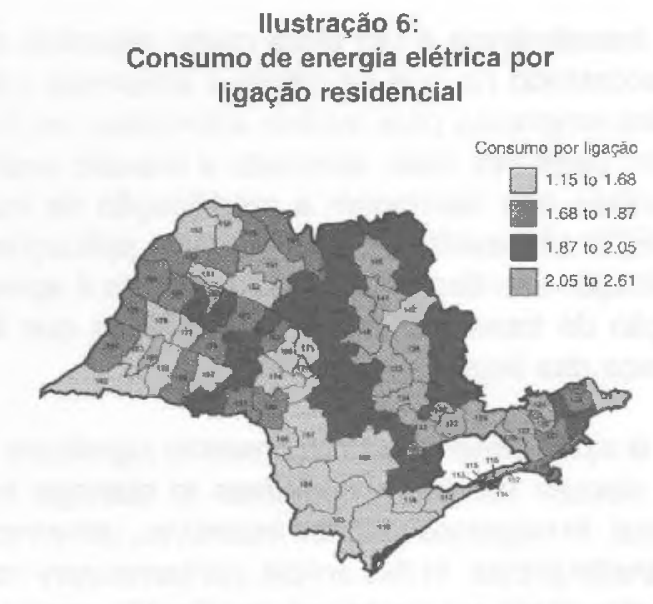

Próximo trabalho. A utilidade deste tipo de procedimento aumenta conforme as áreas representadas tornam-se mais específicas. Esperamos poder retornar em breve ao assunto, com um mapa detalhado dos Setores e Sub-Setores do Município de São Paulo. Neste caso, estaremos tratando de áreas muito pequenas, referentes a grupos de quadras da cidade, com variadas possibilidades de aplicação em marketing e planejamento.
14. Segundo Wurman, por mais que se procure, existem adenas cinco formas de organizar dados: por categoria, tempo, alfabeto, secüêncla e localizacão. Com täo poucas chaves disponiveis, è inaceitáve\} que a iocalização sejă tão negllgenclada. A discussão completa encontra-se num livro fundamental para quem se interessa pelo processo de transformação de dados em informação e de informaçäo em compreensão. o livro é. ademais, absolutamente interessante: Wurman, Richard Saul, Ansiedade de Intormaçăo. Säo Paulo: Lultura, 1991.

15. A correspondente tabela, com dados numèricos poderá ser encontrada no relatório do NPP.

16. Dacios obtidos do Perfil Municipal da Fundação Seade. 